\title{
Comparison of the effect of educational intervention based on adult learning theory and telenursing on self-management among epileptic patients \\ Masoume Arab ${ }^{1}$, Elham Bagheri², Zahra Rahnavard ${ }^{2}$
}

\author{
Journal of Research \& Health \\ Social Development \& Health Promotion \\ Research Center \\ Vol. 6, No. 5, Nov \& Dec 2016 \\ Pages: 522- 529 \\ DOI: 10.18869/acadpub.jrh.6.5.522 \\ Original Article
}

1. Department of Nursing, Faculty of Nursing and Midwifery, Mazandaran University of Medical Sciences, Mazandaran, Iran

2. Department of Community Health Nursing, Faculty of Nursing and Midwifery, Tehran University of Medical Sciences, Tehran, Iran

Correspondence to: Zahra Rahnavard, Department of Community Health Nursing, Faculty of Nursing and Midwifery, Tehran University of Medical Sciences, Tehran, Iran

Email: Zahra.rahnavard@gmail.com

Received: 21 Jan 2014

Accepted: 10 May 2014

How to cite this article: Arab M, Bagheri E, Rahnavard Z. Comparison of the effect of educational intervention based on adult learning theory and telenursing on selfmanagement among epileptic patient. $J$ Research \& Health2016; 6(5): 522- 529.

\begin{abstract}
Epilepsy is one of the most common neurological disorders in the world. Self-management had a significant effect on seizure control and quality of life. This study was conducted to compare of the effect of educational intervention based on adult learning theory with and without telephone fallow up by nurse (Telenursing) on self-management in adult with epilepsy. This study is a randomised controlled trial that done on 120 epileptic patients. Data collection tool was epilepsy self-management scale. Participants who met the inclusion criteria, were randomly assigned to the 3 groups: 1) Those in the education group without telephone follow up received a four-session education based on adult learning theory, 2) Those in the education with telephone follow up group received four session education based on adult learning theory plus 6 sessions telephone follow up by nurse and 3) Those in control group received no intervention. Then all participants had assessed with the same scale. Before intervention there were no significant differences between three groups in demographic data and self-management score. Comparison of three groups after intervention showed that the mean score of self-management scale in first and second group was increased significantly. The results of this study indicate that the educational program based on adult learning theory and telephone fallow up had beneficial effects on selfmanagement behaviors in epileptic patients.
\end{abstract}

Keywords: Education, Epilepsy, Self Care, Telenursing

\section{Introduction}

Epilepsy is one of the most common severe chronic neurological disorders in the world which generates severe debilitating complications. This disease is also considered to have biological, psychological and social consequences [1]. The worldwide prevalence of epilepsy is $16-51$ per 100,000 [2]. It is estimated that about 50 million people suffer from epilepsy worldwide with over $80 \%$ living in developing countries [3]. Epilepsy is the most common neurological disease in Iran, too. Previous studies have shown that nearly $0.5-1 \%$ of the population; about $400-800$ thousands patients, suffer from epilepsy in Iran [4].

The chronic nature of epilepsy and its complications pose great economical burden on the healthcare system. Studies that have 
examined the cost and economic burden of this disease have all indicated that epilepsy has economical impacts on the society in terms of health care needs, premature deaths and weakening economic strength of the country [5].

One of the key and fundamental aspects in controlling epilepsy is self-management. The primary goal of epilepsy management is empowering the patients to modify one's lifestyle as much as possible without being affected by the side effects of medications and psychological complications of seizures [6]. Shore et al. [7] have shown that epilepsy and seizure education programs for patients and their families improve their quality of life and awareness of the disease. Despite the importance of self-management education and follow-up plans for patients with chronic diseases, there are significant barriers to the provision of education, too. The greatest challenge of patients in cooperating with self-management programs is problems associated with geographical distance and lack of transportation, followed by psychological problems such as denial, mood disorders and low self-confidence [8].

One of the suggested solutions to resolve the problem of distance and lack of time is employing telecommunication technologies such as telenursing [9]. Telenursing or remote nursing enables nurses to carry out activities such as education, monitoring patients, data collection, nursing interventions and supporting patients and their family remotely [10].

The employed technologies in telenursing are the internet, telephone, fax, video conferences, and alike, while telephone is increasingly used as the most available communication tool to majority of people and using it does not require any specific skills [11]. Several studies have introduced telephone-based follow-up as the most effective and efficient follow-up method for patients with chronic diseases. Sadeghi et al. [12] and Zakeri-Moghadam et al. [13] have shown in their studies that several weeks of nurse-led telephone-based follow-up for patients with diabetes had improved the blood glucose, glycosylated hemoglobin, and patients' adherence to diet. Also, Paquette et al. [14] proved that telephone follow-up was effective in pain reduction and preventing long-term complications in children undergoing tonsillectomy.

The prevalence of epilepsy in Iran mandates addressing it to improve patients' quality of life. Furthermore, its management needs appropriate attention from the perspective of health policy. The effect of educating adults with epilepsy and telenursing in other countries on one hand and the emphasis on doing more research on the same field [4] on the other hand, had motivated the researcher to conduct a study with the objective of comparing the effect of educational intervention based on Adult Learning Theory (ALT) with and without telenursing on self-management. So if this method proves effective, it would become a basis in implementing routing care for patients with epilepsy in Iran.

\section{Method}

The present study is a Randomised Controlled Trial (RCT) that studied 132 randomly selected samples from the members of Isfahan epilepsy association using random allocation software. With regard to the study of Mc Auley et al. [15] on self-management in patients with epilepsy, $\alpha$ level of $20 \%$ and statistical power of $80 \%, 37$ participants were assigned to three groups. Considering a loss rate of $20 \%, 44$ patients per group were selected. The sampling procedure started with entering the total number of patients (248), number of groups (three), and number of participants per group (44) into the software which generated a list of categorized numbers for each group. Then the name and document ID of each patient were extracted according to the primary list and all participants were assigned to either of the groups as follows: i) patients who received education based on adult learning theory and telephone-based follow-up; ii) patients who only received education based on adult learning theory; iii) patients who received no other intervention 
other than usual care (control group).

The inclusion criteria included being diagnosed with epilepsy for at least six months, consumption of anti-epileptic drugs (AEDs), ability to understand and speak Persian, and having access to telephone. Exclusion criteria included no participation of patients receiving educational programs (Group 1 and Group 2), not answering two or more calls in the telephone follow-up group (Group 1), and unwillingness to continue participation. We did not have any withdrawals.

The data collection tool was a self-report questionnaire in two sections as discussed below:

i) Demographic and disease information checklist: This questionnaire asked about age, gender, level of education, marital status, economic status, employment and insurance status, duration of illness, type of seizures, number of medications, epileptic seizure condition, and comorbidities.

ii) Epilepsy Self-management Scale (ESMS): ESMS was first developed in 26 items by expert consensus [10]. In year 2004, 12 items were added to the questionnaire to study safety and life style management better. Finally, a 38-item scale was developed by Diloria et al. in 2004 in five domains of information management ( 8 items), seizure management (6 items), safety management (6 items), medication management (10 items), and lifestyle management ( 6 items). Each item is scored using a 5-point Likert scale $($ Never $=1$, Seldom $=2$, Sometimes $=3$, Often $=4$, Always $=5$ ) [10]. Ten items are reversely scored including four items in safety management and six items in medication management. The total score of this tool varies from 38 to 190 while the score ranging was 6-30 in seizure management, 8-40 in information management, 6-30 in safety management, $10-50$ in medication management, and 6-30 in lifestyle management. A higher score indicates more frequent use of self-management strategies while lower scores indicate the opposite.

The internal consistency reliability (Cronbach's alpha) was used to determine the scientific reliability of research tool. The questionnaires were provided to 20 members of Epilepsy Association after obtaining their written consent and a Cronbach's alpha was found 0.825 .

Researchers explained research objectives to officials and patients of Isfahan epilepsy association. Out of 248 patients who met the inclusion criteria, 132 were selected and assigned to three groups. After obtaining participants' informed written consents and completing demographic and clinical information questionnaires, ESMS was filled out through blinded interviews conducted by a researcher who was unaware of categorization.

The educational contents of a booklet were provided using literature reviews, electronic sources and websites. Then the booklet was given to three neurologists of Isfahan Epilepsy Association and several professors of the faculty of nursing and midwifery of Tehran university of medical sciences. The required modifications were made according to their recommendations and they were asked to confirm the changes once again. Finally, the questionnaires were handed to patients under educational programs (Group 1 and Group 2) after intervention sessions. The patients of the control group were also provided with the same material at the end of the study.

Educational program: The groups receiving the educational programs (Group 1 and Group 2) were divided into subgroups of 10-12 people. Education was conducted in four 60-minute group question-and-answer sessions based on adult learning theory. The educational content included medical, psychological and social subjects related to self-management skills. The discussion was guided by the researcher while patients were also participating and the educational materials were provided to them. Instructional tools such as video-projectors and whiteboards were used. A booklet titled "Better Life with Epilepsy" and a CD containing lecture slides were provided at the end of each session.

Telephone follow-up: A landline phone 
number and a cell phone number were obtained from Group 1 participants (education with telephone follow-up). After the educational sessions ended, six telephone calls were made over eight weeks (every week for the first month and every other week for the second month) with the content relevant to training sessions.

Participants of all three groups were asked to attend the association's head office two weeks after the last call to have ESMS filled out by the researcher. The participants of the control group (Group 3) received no other interventions than the routine care provided by the association.

All participants were provided with a booklet containing all educational materials discussed during the sessions for observing ethical obligations and a gift for appreciating their cooperation.

The results were interpreted using different analytical techniques according to the type of data. So descriptive statistics as a frequency distribution table, Chi-squared test, Fisher's exact test, and paired t-test were used to determine the impact of education within each group; and ANOVA was used to compare groups before and after the intervention.

All the computation were performed using SPSS version 16 at $p<0.001$ level of significance.

This research was supported by the Deputy Research of Tehran University of Medical Sciences after the university's Ethics Committee confirmed it. The research objectives were explained to authorities and patients of Isfahan Epilepsy Association and written informed consents were obtained from patients. All participants (including the control group) received a booklet and a gift at the end of the test.

\section{Results}

Most of the participants in all groups were women aged 18-28 years, unemployed and had insurance coverage and were economically moderate. Most of the participants within the group receiving education and telephone follow-up (Group 1) and within the control group were married while most of the patients within the group receiving education without telephone follow-up (Group 2) were single. The majority of Group 1 participants had high school diploma or associate degree, while the educational level of higher proportion of participants of Group 2 and control group were below high school diploma (Table 1). Examination of patients in terms of disease symptoms showed that the majority of Group 1 participants were suffering from epilepsy for 6-15 years, participants in the two other groups had the disease 16-25 years. Most of the participants in Group 1 and control group had focal seizures and remained seizurefree for months but Group 2 participants had generalized seizures almost every month. The findings also showed that participants of all groups consumed 2-3 medications on a daily basis to control the seizures and they did not suffer from any other diseases (Table 1).

The three groups were matched for demographic data and disease features (Table 1).

The mean score of self-management was not statistically different among groups before the interventions which indicated that groups were matched $(\mathrm{p}=0.62)$.

Paired-samples t-test was used to evaluate intragroup changes before and after the interventions. According to Table 2, participants who received educational interventions and telephone follow-up acquired the highest mean score in selfmanagement with a statistical difference before and after the intervention. The same results were achieved for the participants who received education with no telephone follow-up $(\mathrm{p}<0.001)$. However, the difference was not significant in the control group $(p<0.92)$. So a post hoc test was conducted to locate the source of difference and the results showed that the difference originated from the individual differences within each group (Table 2). ANOVA showed that the difference between self-management scores was statistically significant within each group $(\mathrm{p}<0.0001)$ (Table 2). 
Table 1 Comparing the demographics and disease characteristics of the patients in the three groups of the study

\begin{tabular}{|c|c|c|c|c|c|}
\hline \multicolumn{2}{|c|}{ Group } & $\begin{array}{l}\text { Education with } \\
\text { Telephone Follow-up }\end{array}$ & $\begin{array}{l}\text { Education without } \\
\text { Telephone Follow-up }\end{array}$ & Control & p-value \\
\hline \multicolumn{2}{|c|}{ Age $(\mathrm{SD}) \pm$ Mean } & $30.15 \pm 8.13$ & $30.03 \pm 9.5$ & $31.1 \pm 10.48$ & $\mathrm{p}=0.97 £$ \\
\hline \multirow{3}{*}{ Sex } & & Percentage & Percentage & Percentage & \multirow{3}{*}{$\mathrm{p}=0.76 €$} \\
\hline & Male & 48.8 & 43.6 & 47.5 & \\
\hline & Female & 51.2 & 56.4 & 52.5 & \\
\hline & & 100 & 100 & 100 & \\
\hline \multirow{4}{*}{ Employment } & Unemployed & 51.2 & 61.5 & 42.5 & \multirow{4}{*}{$\mathrm{p}=0.15 £$} \\
\hline & Government Job & 2.4 & 5.1 & 5 & \\
\hline & $\begin{array}{c}\text { Non- } \\
\text { Government Job }\end{array}$ & 17.1 & 7.7 & 20 & \\
\hline & Housewife & 29.3 & 25.5 & 32.5 & \\
\hline \multicolumn{2}{|c|}{ Total } & 100 & 100 & 100 & \\
\hline \multirow{4}{*}{ Education } & Illiterate & 2.4 & 7.7 & 17.5 & \multirow{4}{*}{$\mathrm{p}=0.18 £$} \\
\hline & $\begin{array}{l}\text { Less than High } \\
\text { School Diploma }\end{array}$ & 43.9 & 51.3 & 47.5 & \\
\hline & $\begin{array}{l}\text { High School } \\
\text { Diploma or } \\
\text { Associate's } \\
\text { Degree }\end{array}$ & 46.3 & 28.2 & 25 & \\
\hline & $\begin{array}{l}\text { Bachelor's } \\
\text { Degree or } \\
\text { Higher }\end{array}$ & 7.3 & 12.8 & 10 & \\
\hline \multicolumn{2}{|c|}{ Total } & 100 & 100 & 100 & \multirow{4}{*}{$\mathrm{p}=0.9 €$} \\
\hline \multirow{3}{*}{ Income } & Low & 29.2 & 23.1 & 30 & \\
\hline & Average & 48.8 & 59 & 50 & \\
\hline & High & 22 & 17.9 & 20 & \\
\hline \multicolumn{2}{|c|}{ Total } & 100 & 100 & 100 & \\
\hline \multirow{2}{*}{ Insurance } & Yes & 75.6 & 74.4 & 85 & \multirow{2}{*}{$\mathrm{p}=0.45$} \\
\hline & No & 24.4 & 25.6 & 15 & \\
\hline \multicolumn{2}{|c|}{ Total } & 100 & 100 & 100 & \\
\hline \multirow{3}{*}{ Marital Status } & Married & 48.8 & 35.9 & 52.5 & \multirow{3}{*}{$\mathrm{p}=0.59 £$} \\
\hline & $\begin{array}{l}\text { Divorced / } \\
\text { Widowed }\end{array}$ & 7.3 & 5.1 & 5 & \\
\hline & Single & 43.9 & 59 & 42.5 & \\
\hline & & 100 & 100 & 100 & \\
\hline \multirow{5}{*}{$\begin{array}{l}\text { Duration of the } \\
\text { Disease }\end{array}$} & $\begin{array}{l}\text { Less than } 5 \\
\text { Years }\end{array}$ & 9.8 & 15.4 & 15 & \multirow{3}{*}{$\mathrm{p}=0.76 €$} \\
\hline & 6 to 15 Years & 41.4 & 28.2 & 30 & \\
\hline & 16 to 25 Years & 36.6 & 35.9 & 35 & \\
\hline & 26 to 35 Years & 9.8 & 17.9 & 17.5 & \\
\hline & $\begin{array}{c}\text { More than } 35 \\
\text { Years }\end{array}$ & 2.4 & 2.6 & 2.5 & \\
\hline \multicolumn{2}{|c|}{ Total } & 100 & 100 & 100 & \\
\hline \multirow{2}{*}{ Seizure Type } & Focal & 52.2 & 41 & 57.5 & \multirow{2}{*}{$\mathrm{p}=0.33 €$} \\
\hline & Generalized & 48.8 & 59 & 42.5 & \\
\hline \multicolumn{2}{|c|}{ Total } & 100 & 100 & 100 & \\
\hline
\end{tabular}

$¥:$ Independent $\mathrm{t}$

$€$ : Chi-square

$£:$ Fisher's 
Table 2 Determining and comparing the self-management of epileptic patients in the three groups before and after the intervention

\begin{tabular}{|c|c|c|c|c|c|c|c|c|}
\hline & & $\begin{array}{l}\text { Before the } \\
\text { Education }\end{array}$ & & & & $\begin{array}{l}\text { After the } \\
\text { Education }\end{array}$ & & \\
\hline & $\begin{array}{l}\text { Education } \\
\text { with } \\
\text { Telephone } \\
\text { Follow-up }\end{array}$ & $\begin{array}{l}\text { Education } \\
\text { without } \\
\text { Telephone } \\
\text { Follow-up }\end{array}$ & Control & p-value & $\begin{array}{l}\text { Education } \\
\text { with } \\
\text { Telephone } \\
\text { Follow-up }\end{array}$ & $\begin{array}{c}\text { Education } \\
\text { without } \\
\text { Telephone } \\
\text { Follow-up }\end{array}$ & Control & $\mathrm{p}$-value \\
\hline & Mean \pm SD & Mean \pm SD & Mean \pm SD & & Mean \pm SD & Mean \pm SD & Mean \pm SD & \\
\hline $\begin{array}{c}\text { Self- } \\
\text { Management }\end{array}$ & $111.4 \pm 12.8$ & $113.4 \pm 14.9$ & $114 \pm 11.2$ & $\mathrm{p}=0.62$ & $158.7 \pm 10.6$ & $144.8 \pm 17.3$ & $115.8 \pm 11.3$ & $\mathrm{p}<0.001$ \\
\hline
\end{tabular}

Paired t-test

\section{Discussion}

The present study confirmed the research hypothesis that providing education based on adult learning theory with and without telenursing can improve self-management behaviors among people with epilepsy. This study also showed that education based on ALT and telephone follow-up can be considered an appropriate strategy for designing and implementing supportive interventions, as well as improving self-management skills and quality of life among epileptic patients.

Yadegari et al. studied 60 patients with epilepsy in Valiasr Hospital in Zanjan. Their study titled "The effect of educational programs on selfmanagement skills of patients with epilepsy" showed that four educational sessions were effective in improving self-management skills of patients. Furthermore, self-management score of patients within the experimental group was statistically different after the intervention and in comparison with control group. Thus, their research results are aligned with results of the current study [16].

Jalilian, Motlagh and Solhi conducted a study that investigated the impacts of implementing educational programs on improving selfmanagement of 120 patients with diabetes type II. Their results indicated that self-management improved in patients receiving interventions after six educational sessions [17].

Naderi et al. research titled "The impact of Precede-Proceed model on quality of life in patients with epilepsy in Baghiatollah Hospital (Tehran)" showed that the difference in the score of quality of life between experimental group and control group was statistically significant after five educational sessions [18].
The study of Saheb-o-zamani et al. showed that education had a significant impact on awareness and performance of patients receiving interventions [19]. The study of Shore et al. suggested that awareness and the quality of life among parents as well as children had improved after a two-day educational intervention [7].

These findings are contradictory to research results of Dilorio et al titled "Telephonebased self-management program for patients with epilepsy". Their study suggested that the overall self-management score among patients with epilepsy was not significant between the intervention group and control group after telephone-based interventions. The reason might be explained by the small sample size of 22 participants in that pilot study [10].

The mean score of self-management in Group 1 was higher than that of Group 2 and control group and this difference was statistically significant. This means that self-management skills increased in the group receiving education and follow-up calls comparing to the group receiving education only and the control group (Table 2).

This finding showed that patients who received education were better at selfmanagement in comparison to the control group; and patients who received education as well as telephone follow-up calls achieved higher self-management scores in comparison to participants who were only provided with the education. The data analysis suggested that telephone follow-up is an effective approach to improve self-management 
behaviors in patients. This result is aligned with similar studies of other chronic diseases such as diabetes. Sadeghi et al. and Zakeri-Moghadam et al. demonstrated similar conclusions with their studies titled "The impact of telenursing on the level of glycosylated hemoglobin in patients with diabetes" [12] and "The impact of telenursing on adhering to diabetic diet in patients with diabetes type II" [13] respectively. These studies showed that blood glucose, glycosylated hemoglobin, and diet adherence were statistically different in the intervention group after several weeks of telenursing.

Considering the effect of education based on adult learning theory and telephone-based follow up in improving self-management behaviors in epileptic patients, nurse managers can exploit the results of the current study to improve knowledge and awareness of nurses on educational needs of patients, the role of selfmanagement in controlling chronic diseases such as epilepsy and the necessity of training patients.

Furthermore, most epileptic patients spend most of their time out of health care centers and hospitals thus it is important to extend cares beyond such centers and cover their whole life. This approach can work only if proper policies are developed to implement educational programs and follow up interventions through hospital personnel especially nurses.

The present research studied patients aged over 18 years. So it is recommended to investigate the impact of education in other age groups and compare the results. Additionally, it is recommended to investigate the impact of other follow up methods in patients with epilepsy such as the internet and text messages.

The individual difference between patients and difficulty in controlling their psychologicalemotional state while answering the questionnaires were some of research limitations that were overcome to some extent by considering a control group and randomly assigning samples to each group.

\section{Conclusion}

Comparing the self-management score before and after the intervention indicated that the group receiving education and telephonebased follow up (Group 1), and the group receiving education without telephone follow up (Group 2) achieved significantly higher self-management scores after the intervention. The findings suggested that education based on ALT and telephonebased follow up could significantly improve self-management behaviors of patients.

The groups were matched for selfmanagement scores before the intervention thus the research hypothesis, indicating a significant difference among the three groups in terms of self-management scores after the intervention, is confirmed. Therefore, it can be concluded that education based on ALT and telenursing can improve selfmanagement behaviors in patients with epilepsy.

Finally, education based on ALT and telenursing can be a tailored approach for designing and implementing supportive interventions, as well as improving selfmanagement skills and quality of life in epileptic patients.

\section{Acknowledgements}

This article is the result of a research project approved by Tehran university of medical sciences No. 18740; 18.5.2013.

We would like to thank the authorities of Tehran education organization, Isfahan society of epilepsy, and the patients who participated in the study.

\section{Contribution}

Study design: MA, EB

Data collection and analysis: MA, EB, ZR

Manuscript preparation: MA, ZR

\section{Conflict of Interest}

"The authors declare that they have no competing interests. "

\section{Funding}

The author (s) received no financial support for the research, authorship and/or publication 
of this article.

\section{References}

1- Laybourne AH, Morgan M, Watkins SH, Lawton R, Ridsdale L, Goldstein LH. Self-management for people with poorly controlled epilepsy: Participants' views of the UK self-management in epilepsy (SMILE) program. Epilepsy Behav2015; 52(Pt A): 159-64.

2- Chen HF, Tsai YF, Lin YP, Shih MS, Chen JC. The relationships among medicine symptom distress, selfefficacy, patient-provider relationship, and medication compliance in patients with epilepsy. Epilepsy Behav2010; 19(1): 43-9.

3- Ngugi AK, Bottomley C, Kleinschmidt I, Sander JW, Newton CR. Estimation of the burden of active and lifetime epilepsy: A meta-analytic approach. Epilepsia2010; 51(5): 883-90.

4- Mohammadi MR, Ghanizadeh A, Davidian H, Mohammadi M, Norouzian M. Prevalence of epilepsy and comorbidity of psychiatric disorders in Iran. Seizure2006; 15(7): 476-82.

5- De Boer HM. Epilepsy stigma: moving from a global problem to global solutions. Seizure2010; 19(10): 630-6. 6- Robinson E, Di Iorio C, De Padilla L, et al. Psychosocial predictors of lifestyle management in adults with epilepsy. Epilepsy Behav2008; 13(3): 523-8. 7- Shore CP, Perkins SM, Austin JK. The seizures and epilepsy education (SEE) Program for families of children with epilepsy: A preliminary study. Epilepsy Behav2008; 12(1): 157-64.

8- Edward KL, Cook M, Giandinoto JA. An integrative review of the benefits of self-management interventions for adults with epilepsy. Epilepsy Behav2015; 45: 195204.

9- Kawaguchi, Takayasu, Telenursing in Chronic Conditions. Telenursing. Springer London, 2011:pp: 6174.

10- Di Iorio C, Reisinger EL, Yeager KA, Mc Carty F. A telephone-based self-management program for people with epilepsy. Epilepsy Behav2009; 14(1): 232-6.

11- Fraser RT, Johnson EK, Miller JW, et al. Managing epilepsy well: self-management needs assessment. Epilepsy Behav2011; 20(2): 291-8.

12- Sadeghi T, Shahabinejad M, Derakhshan R, Balaei P. Effect of nurse-led telephone follow up (Telenursing ) on HbA1c among diabetic patients. Journal of Rafsanjan University of Medical Sciences and Health Services2010; 9(3) :175-84.

13- Zakerimoghadam M, Bassampour S, Rjab A, Faghihzadeh S, Nesari M. Effect of nurse-led telephone follow ups (Tele-Nursing) on diet adherence among type 2 diabetic patients. Journal of Hayat2008; 14(2) :63-71. 14- Paquette J, Le May S, Lachance Fiola J, Villeneuve
E, Lapointe A, Bourgault P. A randomized clinical trial of a nurse telephone follow-up on paediatric tonsillectomy pain management and complications. $J$ Adv Nurs2013; 69(9): 2054-65.

15- Mc Auley JW, Mc Fadden LS, Elliott JO, Shneker BF. An evaluation of self-management behaviors and medication adherence in patients with epilepsy. Epilepsy Behav2008; 13(4): 637-41.

16-Yadegary MA, Dehghan-Naeyeri N, Ali-asgharpoor M, Naseh L. The effect of educational program on drugs self-management in patient with epilepsy-A randomized clinical trial. Journal of Clinical Nursing and Midwifery2013; 2(3) :86-94.

17- Jalilian F, Zinat Motlagh F, Solhi M. Effectiveness of education program on increasing self management among patients with Type II diabetes. Journal of Ilam University of Medical Sciences2012; 20(1): 26-34.

18- Naderi Z, Zigheimat F, Ebadi A, Kachouei H, Mahdizadeh S. Evaluation of the application of the PRECEDE-PROCEED model on the quality of life of people living with epilepsy referring to Baqyatallah hospital in Tehran . Daneshvar Medicine2009; 16(82): $37-44$.

19- Sahebolzamani M, Shakuri A, Aliloo L, Rashidi A. The efficacy of self-care education on knowledge and performance of epileptic patients who referred to selected educational hospitals of tehran university of medical sciences in 2008. Journal of Urmia University of Medical Sciences2010; 20(4): 284-9. 